\title{
Natal habitat-biased dispersal in the Siberian flying squirrel
}

\author{
Vesa Selonen $^{1, *}$, Ilpo K. Hanski ${ }^{2}$ and André Desrochers ${ }^{3}$ \\ ${ }^{1}$ Department of Biological and Environmental Sciences, and ${ }^{2}$ Finnish Museum of Natural History, \\ University of Helsinki, Helsinki 00014, Finland \\ ${ }^{3}$ Centre d'étude de la forêt, Faculté de foresterie et de géomatique, Université Laval, Quebec, Canada G1K 7P4
}

\begin{abstract}
Theoretically, dispersers should target the habitat where prospects for fitness will be highest. Aiming for a habitat similar to the natal area (natal habitat-biased dispersal) has been hypothesized as a probable rule of thumb for dispersers, but has received very little empirical support to date. We investigated similarities between natal and post-dispersal settlement sites with radio-collared Siberian flying squirrels (Pteromys volans $\mathrm{L}$.). Juveniles born in small patches and raised in nests close to patch edge settled in small patches and used nests close to edges after dispersal. In addition, post-dispersal use of dreys (versus cavities) was similar to that observed in natal sites. However, the quality of settlement habitat was unrelated to the quality of the natal site, which suggests that natal experience on average-quality habitats may not lead to ecological traps for flying squirrels. This study provides evidence that habitat selection at the landscape scale is influenced by habitat of natal area.
\end{abstract}

Keywords: population redistribution; imprinting; habitat selection; dispersal strategy

\section{INTRODUCTION}

Dispersal, i.e. one-way movement from a home range, is a major determinant of dynamics and genetic structure of populations (e.g. Clobert et al. 2001). To understand the effects of dispersal, we need knowledge of how dispersing individuals respond to different habitat types and select a new home range (Stamps \& Krishnan 1999). Theoretically, dispersers should target the habitat where fitness will be highest. However, individual optimization in habitat selection or the simple use of 'cues' obtained in the natal area may occur, leading to important differences among individuals. For example, habitat preferences in adults are sometimes influenced by their juvenile experience (Immelmann 1975; Davis \& Stamps 2004). In addition, individuals sometimes differ in terms of the niche that suits them best (Bolnick et al. 2003). Hence, individuals originating from a particular type of habitat might perform better, if they, for innate or experience-based reasons, disperse to a habitat similar to that where they were born, a phenomenon termed 'natal habitat-biased dispersal' (Haughland \& Larsen 2004a,b; Sacks et al. 2005).

Despite these possible sources of variation in dispersal, individual differences in species habitat selection and movement behaviour have received little attention thus far (Bolnick et al. 2003; Dingemanse et al. 2003). Such variation may have implications from speciation to population dynamics and species conservation (Immelmann 1975; Beltman et al. 2004; Davis \& Stamps 2004). Populations composed of individuals with contrasting habitat preferences may, for example, be more stable in the face of competition or predation (Lomnicki 1980). Furthermore,

* Author and address for correspondence: Department of Biological
and Environmental Sciences, University of Helsinki, PO Box 65
(Viikinkaari 1), Helsinki 00014, Finland (vesa.selonen@helsinki.fi). such variation may buffer against loss of particular habitats or recourses and provide genetic variation needed to adapt to changing environments (Durell 2000; Frankham et al. 2002). Differences in dispersers' habitat preferences will also influence occupancy patterns in the landscape, which in turn will affect source-sink dynamics, patch extinction and rates of colonization of empty patches (Hanski \& Singer 2001).

In this article, we test whether habitat characteristics to which newly born Siberian flying squirrels (Pteromys volans L.) were exposed correlate with settlement habitat characteristics at landscape and nest-site scales. Information gained in the natal area may also influence other individual traits (e.g. Dall et al. 2005). Thus, we analysed the relative use of dreys (twig nests) versus cavities in natal and settlement sites. Flying squirrels are nocturnal, arboreal rodents, which nest or roost in tree cavities, nest boxes and dreys in spruce-dominated boreal forests. The onset of natal dispersal takes place during late summer of the birth year. The dispersal period lasts one or a few separate nights and ends when the disperser occupies a patch where it settles (Selonen \& Hanski 2004, 2006).

\section{MATERIAL AND METHODS}

\section{(a) Study areas}

We conducted our study in three landscapes in southern Finland (Iitti, Anjalankoski and Nuuksio). Landscapes included $24 \%$ of potential flying squirrel habitat, i.e. spruce-dominated forest (Selonen et al. 2001). The matrix of each landscape was dominated by managed forest areas and pine forests (for more information on study areas and landscape structure, see Selonen et al. (2001) and Selonen \& Hanski (2004)). The three landscapes were functionally continuous for dispersers, which were able to move between forest patches and visit several patches that they encountered during dispersal (Selonen \& Hanski 2004, 2006). 


\section{(b) Radio tracking}

We used data from 65 dispersing flying squirrels (29 males and 36 females). Juveniles were captured from their nest cavity (natural or nest box) between June and July and radiocollared (Biotrack, UK, mass of collars was $5.3 \mathrm{~g}$, which is approximately $5 \%$ of the weight of dispersing flying squirrels). Radio-telemetry methods were described in detail in Hanski (1998). Batteries of radio collars usually lasted until JanuaryFebruary. During the dispersal period (July-September), flying squirrels were located approximately five times a week (day and night), but less frequently before and after the dispersal period. Dispersal movements occur at night and are usually done in few hours, over one or a few separate nights (Selonen \& Hanski 2004, 2006). Nest sites were located during daytime. Dispersal distances were calculated as a straight line between the natal nest and the final occupied nest. Individuals that moved less than $400 \mathrm{~m}$ from the natal nest were omitted from the data. They were considered philopatric, being still in contact with their mothers' home range (Selonen \& Hanski 2004). Dispersal distances were $0.4-8.7 \mathrm{~km}$ (males: $1.8 \pm 1.7 \mathrm{~km}$ (s.d.) and females: $2.5 \pm$ $2.3 \mathrm{~km}$ on average; I.K. Hanski \& V. Selonen, manuscript).

\section{(c) Natal and settlement patches}

In each landscape, the forest structure is patchy due to forest management, and the life of flying squirrels is much concentrated within spruce patches (Selonen et al. 2001). Thus, patches were selected as focal landscape elements. We defined the 'natal patch' as an individual's birth patch and the 'settlement patch' as the patch where an individual settled for the first winter of its life. In the few cases where individuals nested in more than one patch in natal or settlement site, we used an average for patch metrics, weighted by the number of visits in each patch. Five individuals died soon after dispersal and were omitted from the analyses, because it was uncertain whether they had settled. In addition, three males dispersed within one large forest area and were omitted from the patch analyses, because they did not change patch. They were, however, included in nest-use analysis. For the 57 individuals included in patch analyses, the number of patches between the natal and settlement site was $6.2 \pm 4.7$ patches on average.

Patch sizes were obtained from a GIS based on aerial photographs (for more information, see Selonen et al. (2001)). We also calculated patch sizes corrected for shape by dividing them by their shape index (FRAGSTATS v. 3, McGarigal et al. 2002), thus yielding lower values for elongated patches with little 'interior' forest.

We classified patches into two groups depending on presence or absence of large aspens (Populus tremula) in the patch. The large aspens are the main source of cavities and an important food source (mainly leaves, catkins and buds of deciduous trees) for flying squirrels (Hanski 1998; Hanski et al. 2000). The flying squirrel is closely associated with this tree species, which seems to be reflected also by its fur colour. Thus, the availability of large aspens is probably an important factor determining patch quality (Hanski 1998; Reunanen et al. 2002). To further describe the quality of patches, we counted the proportion of deciduous trees (using a relascope) on 3-8 sampling plots placed near each nest site (Selonen \& Hanski 2004). The proportion of deciduous trees in patches varied from 8 to $56 \%$. The proportion of deciduous trees and availability of aspen were correlated, but the patch might contain many deciduous trees without any large aspens. Data of proportions of deciduous trees were missing from seven occupied patches.

In patches without aspen, flying squirrels were born in nest boxes (height, approx. $50 \mathrm{~cm}$; diameter, approx. $25 \mathrm{~cm}$; entrance hole diameter, $4.5 \mathrm{~cm}$ ), whereas in patches with aspen, juveniles were born mostly in cavities. However, in seven cases in patches with aspen, both cavities and nest boxes were used (the results of this study did not change if nest box versus cavity was selected as a unit of analysis instead of the availability of aspen). The nest boxes were mainly made from spruce (they included the bark of the tree) and located in spruces.

We calculated the distance of used nests from the nearest forest edge in natal and settlement patches. In an earlier study, we found that edges were preferred by flying squirrels, although their association with edges was not very pronounced (Desrochers et al.2003). Besides cavities and nest boxes, flying squirrels used dreys (i.e. nests in the branches of trees prepared from twigs, lichen and moss). We calculated the proportion of days spent in dreys versus cavities/nest boxes. Individuals with more than five day-time locations in natal and settlement patches were included in the analysis (48 individuals).

\section{(d) Statistical analyses}

Squirrels monitored during dispersal often originated from the same natal patch, because the data included juveniles from 33 families (siblings from 1 year or more, all families originated from different patches). In general, siblings dispersed in different directions and distances (V. Selonen \& I.K. Hanski 1998-2004, unpublished data). Consequently, all juveniles included in the analyses settled in different patches. However, to account for possible non-independence of individual dispersal events from the same nest as well as the clustering of data into three landscapes, we used mixed models with landscape as random effect and natal nest ID as a repeated measures subject (SAS Institute 2004, procedure MIXED). To account for unequal numbers of siblings (1-5), we used the Kenward \& Roger (1997) method of determination of error degrees of freedom in all mixed models. When necessary, data were log transformed or arcsine transformed to achieve homogeneity of variances (Levene tests, $p>0.05$ ) and normality of errors (Shapiro-Wilk tests, $p>0.05$ ).

To account for possible effects of neighbouring patches in settlement decisions, we measured spatial autocorrelation of patch sizes within each study landscape (Rosenberg 2001). Spatial autocorrelation of patch sizes was small (Moran's $I<0.15$ ) or non-existent at $1500-2500 \mathrm{~m}$, and non-existent at other scales from 500 to $3000 \mathrm{~m}$. Nevertheless, we controlled for spatial autocorrelation and the availability of nearby post-dispersal habitat, by including in separate models each of the following variables: average size and quality (proportion of patches with aspen versus without aspen) of (i) the ten patches nearest to the settlement patch, (ii) all patches within $500 \mathrm{~m}$ of the settlement patch, and (iii) the patches intersected by the dispersal path (Selonen \& Hanski 2004). Results were similar with all these availability measures and we report only the models with option (ii). For analysis of nest distances from edges, we used patch size (shape corrected) to describe the available distances of nests from the edges in the settlement patch.

To analyse patch quality before versus after dispersal, we used presence or absence of large aspens (binomial) or the proportion of deciduous trees (arcsine-transformed) as dependent variables. For use of dreys, the dependent variable was the proportion of day-time periods each squirrel spent 

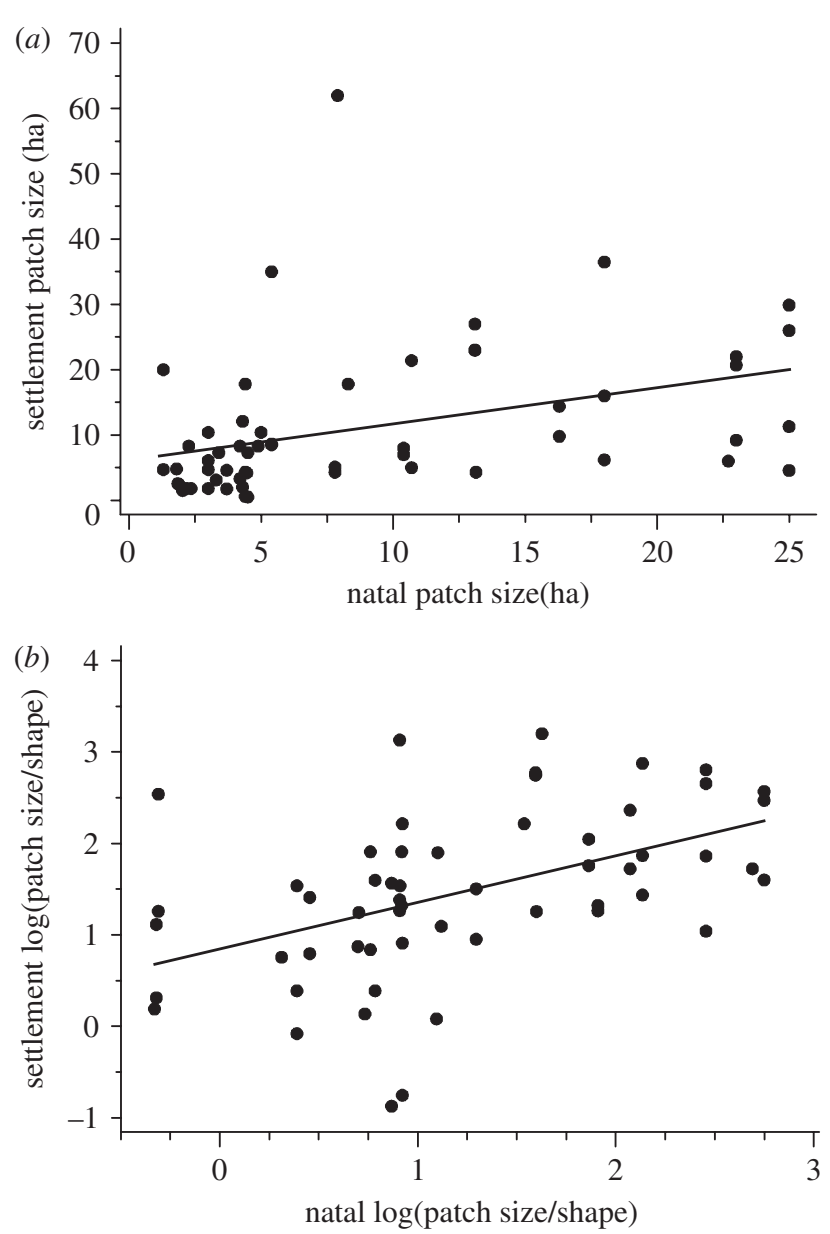

Figure 1. Relationship between natal and settlement patch sizes $((a)$ raw and $(b)$ corrected for shape) in Siberian flying squirrels. Each point represents one squirrel.

resting in dreys (sets of binomial events modelled by 'event/trial' notation; SAS Institute 2004). In models assuming binomial data, we used repeated measures logistic regressions with nest ID as subject (generalized estimation equations with exchangeable covariance structure, Horton \& Lipsitz 1999). The effect of each variable was tested after accounting for all other effects specified in models (type III, SAS Institute 2004). We found no evidence of multicollinearity of independent variables (all $r<0.6$ ).

\section{RESULTS}

Juvenile flying squirrels born in small patches and raised in nests close to patch edges also settled into small patches (figure 1; table 1) and used nests close to edges after dispersal (table 2). However, patch quality did not correlate between natal and settlement sites (presence or absence of large aspens: table 3; proportion of deciduous trees: $F=0.02$, d.f. $=1,44, p=0.9$ ). Only the quality of available patches correlated with the quality of settlement patch (table 3; proportion of deciduous trees: $F=20.6$, d.f. $=1,44, p<0.001)$.

After accounting for all other variables, the use of dreys in the settlement patch was not associated with natal nest type (nest box or cavity; deviance $=0.16, p=0.7$ ), sex (deviance $=0.47, p=0.5$ ), dispersal distance (deviance $=$ $1.16, p=0.3$ ) or patch size (deviance $=2.5, p=0.1$ ). The latter four variables were omitted from the final model with nest ID as a repeated measures subject, to allow convergence
Table 1. Mixed models for post-dispersal patch size (original and shape corrected) in juvenile Siberian flying squirrels. (Landscape was considered a random effect and natal nest ID a repeated measures subject. Correlation between predicted and true post-dispersal patch sizes: $r=0.53$ and 0.52 , respectively.)

\begin{tabular}{|c|c|c|c|c|c|}
\hline \multirow[b]{2}{*}{ fixed effect } & \multirow[b]{2}{*}{ d.f. } & \multicolumn{2}{|c|}{$\begin{array}{l}\text { post-dispersal } \\
\text { patch size }\end{array}$} & \multicolumn{2}{|c|}{$\begin{array}{l}\text { post-dispersal } \\
\text { patch size/ } \\
\text { shape }\end{array}$} \\
\hline & & $F$ & $p$ & $F$ & $p$ \\
\hline natal patch size (log) & 1,50 & 12.65 & 0.0008 & 812.41 & 0.0009 \\
\hline natal patch size $\times$ sex & 1,50 & 0.02 & 0.9 & 0.34 & 0.6 \\
\hline $\operatorname{sex}$ & 1,50 & 0.67 & 0.4 & 1.18 & 0.3 \\
\hline dispersal distance & 1,50 & 0.01 & $>0.9$ & 0.34 & 0.6 \\
\hline $\begin{array}{l}\text { mean patch } \\
\quad \text { size }<500 \mathrm{~m}\end{array}$ & 1,50 & 1.01 & 0.3 & 0.62 & 0.4 \\
\hline $\begin{array}{l}\text { mean patch } \\
\quad \text { size }<500 \mathrm{~m} \times \text { sex }\end{array}$ & 1,50 & 0.50 & 0.5 & 0.24 & 0.6 \\
\hline
\end{tabular}

Table 2. Mixed models for post-dispersal distance between the nest and the nearest forest edge in juvenile Siberian flying squirrels. (Landscape was considered a random effect and natal nest ID a repeated measures subject. Correlation between predicted and true post-dispersal edge distances: $r=0.78$.)

\begin{tabular}{llrc}
\hline fixed effect & d.f. & \multicolumn{1}{c}{$F$} & \multicolumn{1}{c}{$p$} \\
\hline natal distance to edge & $1,41.2$ & 6.75 & 0.01 \\
natal distance to edge $\times$ sex & $1,46.3$ & 0.01 & $>0.9$ \\
sex & $1,46.6$ & 0.01 & $>0.9$ \\
dispersal distance & $1,39.2$ & 0.35 & 0.6 \\
post-dispersal patch size/ & $1,41.2$ & 11.48 & 0.002 \\
$\quad$ shape & & & \\
\hline
\end{tabular}

in the parameter estimation procedure. Unsurprisingly, juveniles in patches without aspen used dreys proportionately more than in patches with aspen ( $n=32$ families, deviance $=8.8, p=0.003$ ). However, juveniles that used dreys relatively frequently in natal patch also tended to use them frequently in the settlement patch, after accounting for availability of aspen (figure 2 ; deviance $=5.8, p=0.02$ ). Cases where settled individuals were unable to find cavities may have obscured the correlation between natal and postsettlement drey use. When individuals not using cavities or nest boxes in the settlement patch were omitted from analysis, results were similar, but evidence for a natal settlement correlation in drey use was indeed stronger $(n=$ 20 families, deviance $=7.5, p=0.006$ ).

Settlement patches tended to be of lower quality than natal patches, and dispersers used dreys more frequently after dispersal (table 4). Patches without aspen used for settlement obviously lacked aspen cavities, but in three cases, a cavity in alder or birch and in seven cases a nest box was used. The remaining individuals (15 out of 25) used only dreys in patches without aspen. The size of natal and settlement patches did not differ (table 4).

\section{DISCUSSION}

Post-dispersal settlement of the Siberian flying squirrel was influenced by patch size and nest location in the natal site. Additionally, the use of dreys after dispersal reflected 
Table 3. Repeated-measures logistic regression for post-dispersal patch quality (absence or presence of large aspens) in juvenile Siberian flying squirrels.

\begin{tabular}{|c|c|c|c|c|c|}
\hline & coefficient & s.e. & change in deviance & d.f. & $p$ \\
\hline sex (female relative to male) & -0.56 & 0.65 & 0.73 & 1 & 0.4 \\
\hline post-dispersal patch size & 0.11 & 0.07 & 1.82 & 1 & 0.2 \\
\hline dispersal distance & -0.0001 & 0.0001 & 0.52 & 1 & 0.5 \\
\hline $\begin{array}{l}\text { natal patch quality (absence of } \\
\text { aspen relative to presence) }\end{array}$ & -0.79 & 0.66 & 1.35 & 1 & 0.2 \\
\hline patch quality $<500 \mathrm{~m}$ & 4.4 & 1.7 & 6.25 & 1 & 0.01 \\
\hline
\end{tabular}

${ }^{a}$ From patches with aspen $61 \%$ or $25 / 41$ and from patches without aspen $44 \%$ or $7 / 16$ of individuals dispersed to patches with aspen.

drey use in the natal site. However, the quality of settled sites, i.e. the availability of large aspens and the proportion of deciduous trees within the patch, was not biased towards the quality of natal sites.

The observed natal habitat-biased dispersal could be a consequence of experience gained during natal phase (e.g. Davis \& Stamps 2004) or, alternatively, there might be genetically determined niche differences between individuals (e.g. Bolnick et al. 2003). The process behind flying squirrels' drey and habitat use differences remains unknown, but differences in natal experience seem a more plausible explanation. Individuals nesting near edges do not, for example, avoid moving also to interior areas (V. Selonen \& I.K. Hanski 1998-2004, unpublished data). In addition, only the tendency to spend time in dreys varied. Whereas there seemed to be no variation, innate or experience based, in dispersers' response to habitat quality and all individuals apparently sought settlement patches with cavities (also Selonen \& Hanski 2004). It may be that the experience gained during natal phase determined where flying squirrels expected to find a good-quality site to settle, consistent with the 'habitat cueing hypothesis' (Stamps 2001). Based on this hypothesis, preference for stimuli comparable to those in the natal habitat would determine where dispersing individuals expect to locate suitable habitat. This might increase genetic variance in the population and possibly lead to microevolution (Davis \& Stamps 2004) or the development of 'behavioural syndromes' (Sih et al. 2004) in some cases.

The effects of the observed individual variation in nest and habitat use on fitness or population dynamics in this flying squirrel population remain unclear. However, natal dispersal is the main form of population redistribution in flying squirrels (Selonen \& Hanski 2004, 2006). Thus, variation in juveniles' dispersal behaviour probably influences genetic structure of the population. In addition, the observed individual variation in drey use may be important for the flying squirrel population in coping with parasitism and predation. Frequent use of dreys by flying squirrels may be important for avoiding fleas, which is one reason for frequent nest-site changes in mammals (Butler \& Roper 1996). The negative side of drey use is that predation risk is probably higher in dreys than in cavities, as the latter protect flying squirrels from all of their main predators. For example, the pine marten (Martes martes) is probably able to invade a drey, but unable to invade a cavity. Microtemperature differences may also occur between dreys and cavities.

Dreys were used proportionately more and patch quality tended to be lower in settlement sites than in natal sites. This could indicate source-sink dynamics in

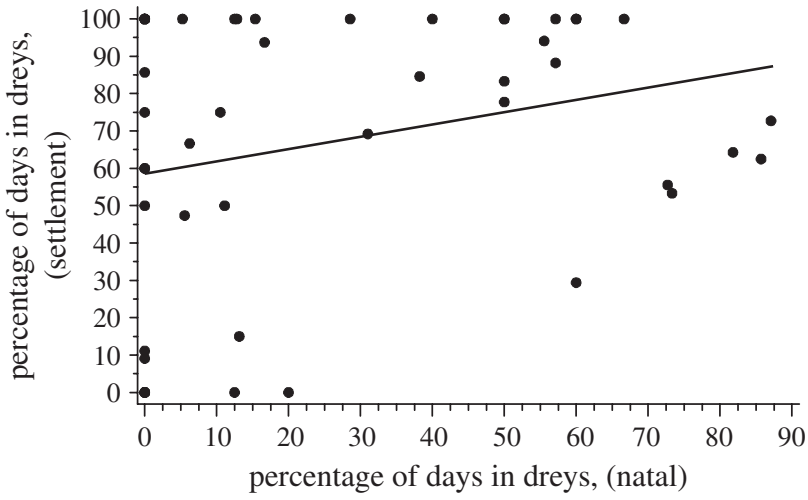

Figure 2. Days rested in dreys in natal and settlement patches in Siberian flying squirrels. Each point represents one squirrel.

this study population or, alternatively, dispersers could occupy cavities and good-quality sites later after the death of residents. However, flying squirrels generally stay in the areas where they have settled after natal dispersal (I.K. Hanski \& V. Selonen, manuscript). The above-mentioned processes did not cause the observed correlation in individual drey use between natal and settlement sites. Indeed, the observed correlation was stronger, when individuals unable to occupy a cavity were omitted from the data. Instead, a lack of correlation between natal habitat quality and habitat quality at settlement sites could be caused by residents excluding dispersers from goodquality patches proportionally more often than from average-quality patches. Unfortunately, we did not have data on interaction between dispersers and residents, but some sex-specific interaction is probably taking place (e.g. Wauters \& Dhondt 1993; Stamps \& Krishnan 1999). Male flying squirrels live in overlapping home ranges, but the spatial distribution of female flying squirrels suggests that they are territorial during the breeding season (Selonen et al. 2001; Rantala 2003). However, no female-female (or male-male) aggression has been observed (Rantala 2003). In addition, dispersers generally seem to be good at locating good-quality patches, although these are scarce in the landscape (Selonen \& Hanski 2004, unpublished data). Thus, it remains uncertain whether residents try to exclude dispersers from occupied patches.

Natal habitat-biased dispersal has been hypothesized in many different taxa, but remains very poorly studied (Vogl et al. 2002; Bolnick et al. 2003; Davis \& Stamps 2004). For example, in a review of the effects of early experience on habitat selection, Davis \& Stamps (2004) found only one study addressing this question for mammals (Wecker 1963). The study by Wecker (1963) addressed coarse 
Table 4. Mean values for natal and post-dispersal settlement patches in juvenile Siberian flying squirrels.

\begin{tabular}{lcll}
\hline & natal patch & settlement patch & test \\
\hline size (ha) & $9.1 \pm 7.6$ & $11.2 \pm 11.3$ & $t_{56}=-0.92, p=0.36^{\mathrm{a}}$ \\
$\begin{array}{l}\text { availability of large aspen } \\
\text { no. without aspen }\end{array}$ & 16 & 25 & $\chi^{2}=3.09, p=0.08^{\mathrm{b}}$ \\
no. with aspen & 41 & 32 & $t_{49}=2.11, p=0.04^{\mathrm{a}}$ \\
deciduous trees (\%) & $23.1 \pm 11.8$ & $20.3 \pm 14.4$ & $t_{56}=-1.11, p=0.27^{\mathrm{a}}$ \\
nest distance from edge (m) & $22.5 \pm 15.2$ & $24.6 \pm 14.6$ & \\
number of nests used & $1.9 \pm 1.1$ & $1.3 \pm 1.4$ & \\
cavities/nest boxes & $1.4 \pm 1.3$ & $3.0 \pm 1.4$ & $n=48, Z=5.06, p<0.0001^{\mathrm{c}}$ \\
dreys & $13.0 \pm 9.9$ & $12.3 \pm 6.2$ & $67.4 \pm 35.9$ \\
no. of daytime radio fixes & $27.0 \pm 28.8$ & & \\
days rested in dreys $(\%)$ & & & \\
\hline
\end{tabular}

a Paired $t$-test.

b $2 \times 2$ table.

${ }^{\mathrm{c}}$ Wilcoxon signed rank test.

habitat types (forest versus fields), the exposure to which had lasting influences on juvenile mice (Peromyscus maniculatus). A few recent mammalian studies provide population genetic evidence for natal habitat-biased dispersal. In the California coyote (Canis latrans), the population was genetically subdivided according to habitat bioregions, supporting the hypothesis that coyote exhibits a dispersal bias towards their natal habitat type (Sacks et al. 2004, 2005; Pilot et al. 2006). Similarly, young North American red squirrels (Tamiasciurus hudsonicus) originating from adjacent patches of different habitats tended to settle in habitat of natal site (Haughland \& Larsen 2004a,b).

An important difference between the study by Haughland \& Larsen $(2004 a, b)$ and ours is that young red squirrels nested in very contrasting types of habitats, i.e. mature closed forest versus thinned open forest that influenced settlement patterns of the species. For flying squirrels, nest boxes in forest patches, which otherwise might remain unoccupied, probably added variation in quality to that naturally existing among patches, but apparently without effects on settlement decisions. Flying squirrels are found in a much narrower range of habitats than the red squirrel (Hanski et al. 2000; Selonen et al. 2001), owing to their close association with aspen. Consequently, there might be genetically determined adaptations to aspen in flying squirrels, which would limit the degree to which experience influences habitat selection. For example, studies on grey squirrel (Sciurus carolinensis) foraging behaviour shows that there are innate factors in the species association with oak trees (Quercus sp.; Steele et al. 2006).

In general, a problematic consequence of experiencebased habitat selection for conservation is that species lured to low-quality habitats, for example with nest boxes, could be doomed also to settle in average-quality habitats. Given that the Siberian flying squirrel is vulnerable in Finland and is protected by an EU habitat directive (Anonymous 1992), the observation that natal habitat does influence adult habitat might have management implications for the species (Donovan \& Thompson 2001; Schlaepfer et al. 2002). In particular, post-natal exposure to low-quality habitats could lead to 'ecological traps' for the species (Dwernychuk \& Boag 1972; Schlaepfer et al. 2002). The ecological trap concept has recently gained much theoretical attention (e.g. Donovan \& Thompson 2001; Schlaepfer et al. 2002), but it remains unclear how often and in which situation this phenomenon may actually occur (Battin 2004). In our study population, not all characteristics of the habitat selected were influenced by the natal habitat, and the apparent lack of natal influence on the key (fitnessconferring) habitat characteristics could decrease the possibility for ecological traps to occur.

This study provides behavioural support for the natal habitat-biased dispersal hypothesis and illustrates it at the landscape scale. Given population-genetic (e.g. Sacks et al. 2005) and theoretical evidence, as well as empirical evidence from imprinting studies (e.g. Davis \& Stamps 2004; Stamps \& Davis 2006; Slagsvold \& Wiebe 2007), there are reasons to believe that such a phenomenon is widespread among mammals and other taxa. Therefore, individual differences in habitat preferences should be better recognized in ecological and evolutionary biological analysis (Bolnick et al. 2003; Davis \& Stamps 2004).

This research adhered to all legal requirements and institutional guidelines in Finland for the use of animals in research.

We thank Mikko Hannonen, Petri Ihalempiä, Maarit Jokinen, Eva Kallio, Henna Piha, Heikki Savolainen, Paul Stevens and Hanna Uusimaa for helping in the field. Sophie Calmé gave valuable comments on earlier drafts of the manuscript. The study was financially supported by Finnish Ministries of Environment and Education, the Ella and Georg Ehrnrooth Foundation, the Kone Foundation, the Maj and Tor Nessling Foundation and the Oskar Öflund Foundation.

\section{REFERENCES}

Anonymous 1992 Council directive 92/43/EEC. Official Journal of the European Communities.

Battin, J. 2004 When good animals love bad habitats: ecological traps and the conservation of animal populations. Conserv. Biol. 18, 1482-1491. (doi:10.1111/ j.1523-1739.2004.00417.x)

Beltman, J. B., Haccou, P. \& ten Cate, C. 2004 Learning and colonisation of new niches: a first step towards speciation. Evolution 58, 35-46.

Bolnick, D. I., Svanback, R., Fordyce, J. A., Yang, L. H., Davis, J. M., Hulsey, C. D. \& Forister, M. L. 2003 The ecology of individuals: incidence and implications of individual specialisation. Am. Nat. 160, 1-28. (doi:10. 1086/343878)

Butler, J. M. \& Roper, T. J. 1996 Ectoparasites and sett use in European badgers. Anim. Behav. 52, 621-629. (doi:10. 1006/anbe.1996.0203) 
Clobert, J., Danchin, E., Dhondt, A. A. \& Nichols, J. D. 2001 Dispersal. Oxford, UK: Oxford University Press.

Dall, S. R. X., Giraldeau, L.-A., Olsson, O., McNamara, O. J. M. \& Stephens, D. V. 2005 Information and its use by animals in evolutionary ecology. Trends Ecol. Evol. 20, 187-193. (doi:10.1016/j.tree.2005.01.010)

Davis, J. M. \& Stamps, J. A. 2004 The effect of natal experience on habitat preferences. Trends Ecol. Evol. 19, 411-416. (doi:10.1016/j.tree.2004.04.006)

Desrochers, A., Hanski, I. K. \& Selonen, V. 2003 Siberian flying squirrel responses to high- and low- contrast forest edges. Landscape Ecol. 18, 543-552. (doi:10.1023/ A:1026006311944)

Dingemanse, N. J., Both, C., van Noordwijk, A. J., Rutten, A. L. \& Drent, P. J. 2003 Natal dispersal and personalities in great tits (Parus major). Proc. R. Soc. B 270, 741-747. (doi:10.1098/rspb.2002.2300)

Donovan, T. M. \& Thompson III, F. R. 2001 Modeling the ecological trap hypothesis: a habitat and demographic analysis for migrant songbirds. Ecol. Appl. 11, 871-882. (doi: $10.2307 / 3061122$ )

Durell, S.E.A. Le V. dit 2000 Individual feeding specialisation in shorebirds: population consequences and conservation implications. Biol. Rev. 75, 503-518.

Dwernychuk, L. W. \& Boag, D. A. 1972 Ducks nesting in association with gulls-an ecological trap? Can. F. Zool. 50, 559-563.

Frankham, R., Ballou, J. D. \& Briscoe, D. A. 2002 Introduction to conservation genetics. Cambridge, UK: Cambridge University Press.

Hanski, I. \& Singer, M. C. 2001 Colonization and oviposition preference in butterfly metapopulations. Am. Nat. 158, 341-353. (doi:10.1086/321985)

Hanski, I. K. 1998 Home ranges and habitat use in the declining flying squirrel, Pteromys volans, in managed forests. Wildl. Biol. 4, 33-46.

Hanski, I. K., Stevens, P. C., Ihalempiä, P. \& Selonen, V. 2000 Home-range size, movements, and nest-site use in the Siberian flying squirrel, Pteromys volans. F. Mammal. 81, 798-809. (doi:10.1644/1545-1542(2000)081<0798: HRSMAN > 2.3.CO;2)

Haughland, D. L. \& Larsen, K. W. $2004 a$ Ecology of North American red squirrels across contrasting habitats: relating natal dispersal to habitat. f. Mammal. 85, 225-236. (doi:10.1644/BWG-113)

Haughland, D. L. \& Larsen, K. W. $2004 b$ Exploration correlates with settlement: red squirrel dispersal in contrasting habitats. F. Anim. Ecol. 73, 1024-1034. (doi:10.1111/j.0021-8790.2004.00884.x)

Horton, N. J. \& Lipsitz, S. R. 1999 Review of software to fit generalized estimating equation regression models. $\mathrm{Am}$. Stat. 53, 160-169. (doi:10.2307/2685737)

Immelmann, K. 1975 Ecological significance of imprinting and early learning. Annu. Rev. Ecol. Syst. 6, 15-37. (doi:10.1146/annurev.es.06.110175.000311)

Kenward, M. G. \& Roger, J. H. 1997 Small sample inference for fixed effects from restricted maximum likelihood. Biometrics 53, 983-997. (doi:10.2307/2533558)

Łomnicki, A. 1980 Regulation of population density due to individual differences and patchy environment. Oikos 35, 185-193. (doi:10.2307/3544426)

McGarigal, K., Cushman, S. A., Neel, M. C. \& Ene, E. 2002 FRAGSTATS: spatial pattern analysis program for categorical maps. Computer software program produced by the authors at the University of Massachusetts Amherst, MA. See http:// www.umass.edu/landeco/research/fragstats/fragstats.html.

Pilot, M., Jedrzejewski, W., Branicki, W., Sidorovich, V. E., Jedrzejewska, B., Stachura, K. \& Funk, S. M. 2006
Ecological factors influence population genetic structure of European grey wolves. Mol. Ecol. 15, 4533-4553. (doi:10.1111/j.1365-294X.2006.03110.x)

Rantala, S. 2003 Mating patterns of the Siberian flying squirrel in Finland. Master's thesis, University of Helsinki.

Reunanen, P., Mönkkönen, M. \& Nikula, A. 2002 Habitat requirements of the Siberian flying squirrel in northern Finland: comparing field survey and remote sensing data. Ann. Zool. Fenn. 39, 7-20.

Rosenberg, M. S. 2001 PASSAGE. Pattern analysis, spatial statistics, and geographic exegesis. Tempe, AZ: Department of Biology, Arizona State University.

Sacks, B. N., Brown, S. K. \& Ernest, H. B. 2004 Population structure of California coyotes corresponds to habitatspecific breaks and illuminates species history. Mol. Ecol. 13, 1265-1275. (doi:10.1111/j.1365-294X.2004.02110.x)

Sacks, B. N., Mitchell, B. R., Williams, C. L. \& Ernest, H. B. 2005 Movements and social structure along a cryptic population genetic subdivision in the coyote. Mol. Ecol. 14, 1241-1249. (doi:10.1111/j.1365-294X.2005.02473.x)

SAS Institute 2004 SAS/online doc, 9.1.3. Cary, NC: SAS Institute, Inc.

Schlaepfer, M. A., Runge, M. C. \& Sherman, P. W. 2002 Ecological and evolutionary traps. Trends Ecol. Evol. 17, 474-481. (doi:10.1016/S0169-5347(02)02580-6)

Selonen, V. \& Hanski, I. K. 2004 Young flying squirrels (Pteromys volans) dispersing in fragmented forests. Behav. Ecol. 15, 564-571. (doi:10.1093/beheco/arh049)

Selonen, V. \& Hanski, I. K. 2006 Habitat exploration and use in dispersing juvenile flying squirrels. F. Anim. Ecol. 75, 1440-1449. (doi:10.1111/j.1365-2656.2006.01168.x)

Selonen, V., Hanski, I. K. \& Stevens, P. C. 2001 Space use of the Siberian flying squirrel Pteromys volans in fragmented forest landscapes. Ecography 24, 588-600. (doi:10.1034/ j.1600-0587.2001.d01-214.x)

Sih, A., Bell, A. \& Johnson, J. C. 2004 Behavioral syndromes: an ecological and evolutionary overview. Trends Ecol. Evol. 19, 372-378. (doi:10.1016/j.tree.2004.04.009)

Slagsvold, T. \& Wiebe, K. L. 2007 Learning the ecological niche. Proc. R. Soc. B 274, 19-23. (doi:10.1098/rspb. 2006.3663)

Stamps, J. A. 2001 Habitat selection by dispersers: integrating proximate and ultimate approaches. In Dispersal (eds J. Colbert, E. Danchin, A. A. Dhondt \& J. D. Nichols), pp. 230-242. New York, NY: Oxford University Press.

Stamps, J. A. \& Davis, J. M. 2006 Adaptive effects of natal experience on habitat selection by dispersers. Anim. Behav. 72, 1279-1289. (doi:10.1016/j.anbehav.2006.03.010)

Stamps, J. A. \& Krishnan, V. V. 1999 A learning based model of a territory establishment. Q. Rev. Biol. 74, 291-317. (doi:10.1086/393163)

Steele, M. A., Manierre, S., Genna, T., Contreras, T. A., Smallwood, P. D. \& Pereira, M. E. 2006 The innate basis of food-hoarding decisions in grey squirrels: evidence for behavioural adaptations to the oaks. Anim. Behav. 71, 155-160. (doi:10.1016/j.anbehav.2005.05.005)

Vogl, W., Taborsky, M., Taborsky, B., Teuschl, Y. \& Honza, M. 2002 Cuckoo females preferentially use specific habitats when searching for host nests. Anim. Behav. 64, 843-850. (doi:10.1006/anbe.2003.1967)

Wauters, L. \& Dhondt, A. A. 1993 Immigration pattern and success in red squirrels. Behav. Ecol. Sociobiol. 33, 159-167. (doi:10.1007/BF00216596)

Wecker, S. C. 1963 The role of early experience in habitat selection by the prairie deer mouse, Peromyscus maniculatus bairdi. Ecol. Monogr. 33, 307-325. (doi:10.2307/1950749) 